\title{
Extrapulmonary sequestration with a left internal thoracic arterial feeding vessel in an infant treated with video-assisted thoracoscopic resection: a case report
}

\author{
Laura DiChiacchio ${ }^{1 *}$ (D) Clint D. Cappiello ${ }^{2}$ and Jose Greenspon ${ }^{2}$
}

\begin{abstract}
Background: Congenital lung malformations exist along a spectrum of pathogenesis and disease severity. Extrapulmonary sequestration (EPS), in which nonfunctional lung tissue develops without connection to the tracheobronchial tree, is one rare manifestation of this disease. Atypical vascular anatomy with a systemic feeding vessel characterizes these lesions.

Case presentation: A 3 day old, 37 week gestation infant underwent chest $X$-ray for confirmation of umbilical catheter placement and was found to have an elevated left hemidiaphragm consistent with eventration versus congenital diaphragmatic hernia. He remained asymptomatic and was evaluated as an outpatient at the age of 9 months, where CT angiogram demonstrated extrapulmonary versus intrapulmonary sequestration with a systemic feeding vessel from the left internal mammary artery.

Conclusions: It is exceedingly rare for the feeding artery to arise from the internal mammary; two such cases have been reported to date, both in adult patients. Here we present a third case of EPS with arterial supply from the internal mammary successfully treated with video-assisted thoracoscopic resection in a 9 month old infant.
\end{abstract}

Keywords: Extrapulmonary sequestration, Video-assisted thoracoscopic surgery, Pediatric, Internal thoracic artery

\section{Background}

Extrapulmonary sequestration is a rare congenital lung disease with variable presentation. Treatment is surgical resection, and initial experiences universally employed thoracotomy. Thoracoscopy is being increasingly utilized for pulmonary resections for many etiologies in both pediatric and adult patients, including pulmonary sequestration [1-3]. Here we present a case of extralobar pulmonary sequestration with vascular supply from the left internal mammary artery resected thoracoscopically without surgical complication in a 9 month old child.

\footnotetext{
* Correspondence: Idichiacchio@som.umaryland.edu

${ }^{1}$ Department of Surgery, Univeristy of Maryland Medical Center, Baltimore 21201, USA

Full list of author information is available at the end of the article
}

\section{Case presentation}

Initial presentation of this patient was on day 3 of life; he is a former 37 week, 4 day gestation infant requiring treatment of hypoglycemia secondary to maternal gestational diabetes after emergency $\mathrm{C}$-section delivery due to decreased fetal activity. Routine plain radiograph was obtained for confirmation of umbilical vein catheter placement. This revealed opacification of the left lung fields and was initially viewed as consistent with pneumonia (Fig. 1). A diagnostic thoracic ultrasound was performed which demonstrated the left lobe of the liver corresponding to the area of opacification with concern for left hemidiaphragm eventration versus congenital diaphragmatic hernia. As the patient was hemodynamically normal with no respiratory symptoms, repeat imaging in 1-2 months was recommended. The

(c) The Author(s). 2018 Open Access This article is distributed under the terms of the Creative Commons Attribution 4.0 International License (http://creativecommons.org/licenses/by/4.0/), which permits unrestricted use, distribution, and 


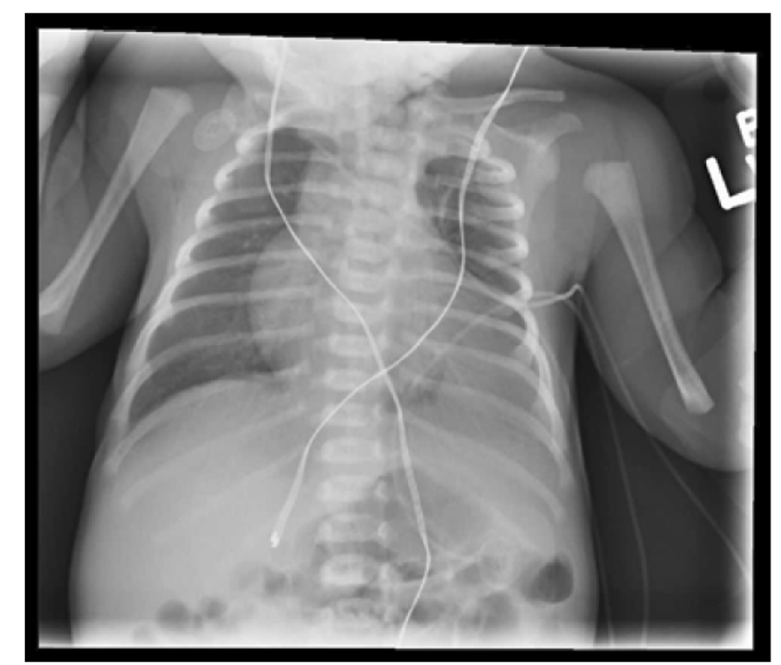

Fig. 1 Pre-operative Chest X-Ray. Initial presenting chest X-ray demonstrating left lower lobe opacification

patient re-presented at 2 months of age with respiratory synctitial virus (RSV) bronchiolitis which resolved with supportive care; interval chest X-ray at this time demonstrated a stable opacity. At 9 months of age an outpatient CT angiogram of the chest was obtained which

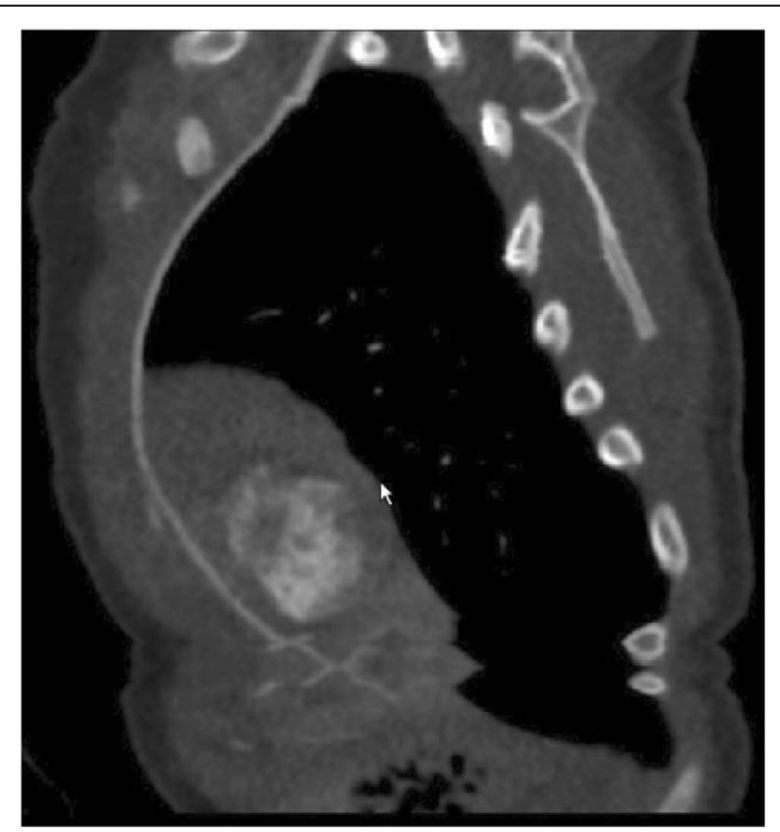

Fig. 2 Pre-operative CT angiogram. Sagittal view obtained from pre-operative $\mathrm{CT}$ angiogram demonstrating left lower lobe sequestration with blood supply from the left internal thoracic artery demonstrated extrapulmonary versus intrapulmonary sequestration with a systemic feeding vessel from the left internal mammary artery (Fig. 2). He underwent elective video assisted thoracoscopic resection of the lesion, which was found to be a left lower lobe extrapulmonary sequestration without communication to the tracheobronchial tree with feeding vessel off the internal mammary as seen on pre-operative CT angiogram. (Fig. 3). Diaphragmatic plication was considered, but not performed due to the asymptomatic nature of this patient's disease. Intubation was achieved with a single lumen cuffed 4-0 endotracheal tube. Complete resection was achieved without complication utilizing two $5 \mathrm{~mm}$ ports, a 30 degree thoracoscope, and an enlarged port site for removal of the specimen. Histology was consistent with extrapulmonary sequestration. He recovered uneventfully and was thriving at his 1 month post-operative visit, notably with persistent but asymptomatic hemidiaphragm elevation on chest X-Ray (Fig. 4).

\section{Discussion and conclusions}

Extrapulmonary sequestration occurs when nonfunctional lung tissue develops from the anterior foregut as an accessory lung bud and remains in the abdomen or chest without connection to the tracheobronchial tree. Its incidence is approximately $0.1 \%$ in the general population and in $10-15 \%$ of cases the tissue is extralobar (as opposed to intralobar). Those cases that occur in an extralobar fashion tend to associate with other congenital anomalies and on average present earlier, and with increased severity, when compared to intralobar presentations $[1,2]$.

Definitive treatment of extrapulmonary sequestration is resection. Movement toward a minimally invasive, thoracoscopic approach in the management of surgical lung disease has been widely adopted [3, 4]. In the pediatric population, and particularly in those patients with congenital anomalies that may relatively contraindicate single lung ventilation, the utilization of minimally invasive techniques remains surgeondependent. Pediatric patients present the technical challenge of small size, narrow intercostal spaces, and associated difficulty visualizing intrathoracic structures utilizing a minimally invasive thoracoscopic approach [5].

Recent reviews of thoracoscopy versus thoracotomy in a pediatric population found similar outcomes in case matched control studies [6-8]. Pre-operative imaging is integral to the safety and efficacy of these practices. While pulmonary angiography is arguably the gold standard for characterizing extrapulmonary sequestration and other congenital lung disease, CT angiogram in practice has been equivalent and 


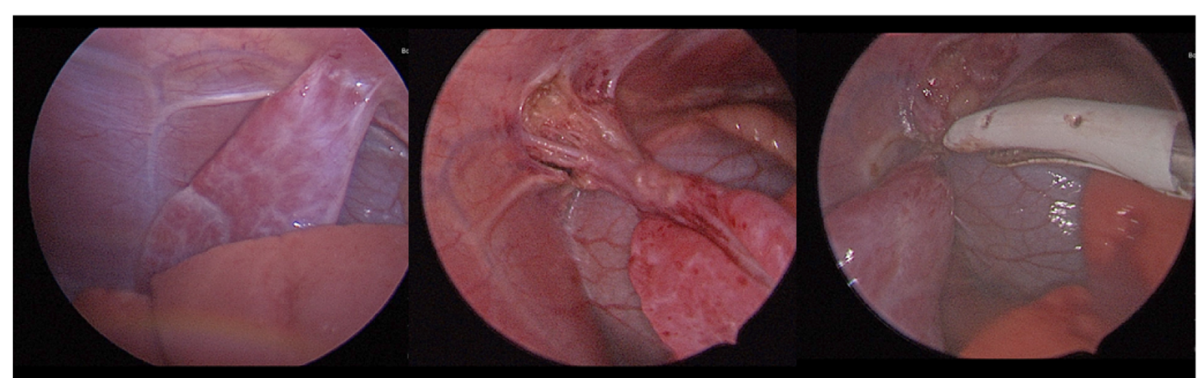

Fig. 3 Intra-operative Findings. Steps of left lower lobe sequestration resection off of the chest wall with a view of the left internal thoracic artery

sufficient for exceptional safety and confidence when entering the operating room for a thoracoscopic resection [9]. In this case, the left internal thoracic artery was identified on pre-operative CT angiogram as the systemic feeding vessel. Only two cases with similar anatomy have been reported to date, both in adult patients. The first of these patients presented with the left internal thoracic artery and pulmonary vein as systemic arterial and venous vessels, respectively; the second presented with two feeding arterial vessels, one the right internal thoracic and the other arising from the right renal artery $[10,11]$. Here we present a third case with internal thoracic arterial supply, and provide an example of the reliability of pre-operative CT angiography and thoracoscopic techniques for complete resection in an anatomically challenging case in a pediatric patient.

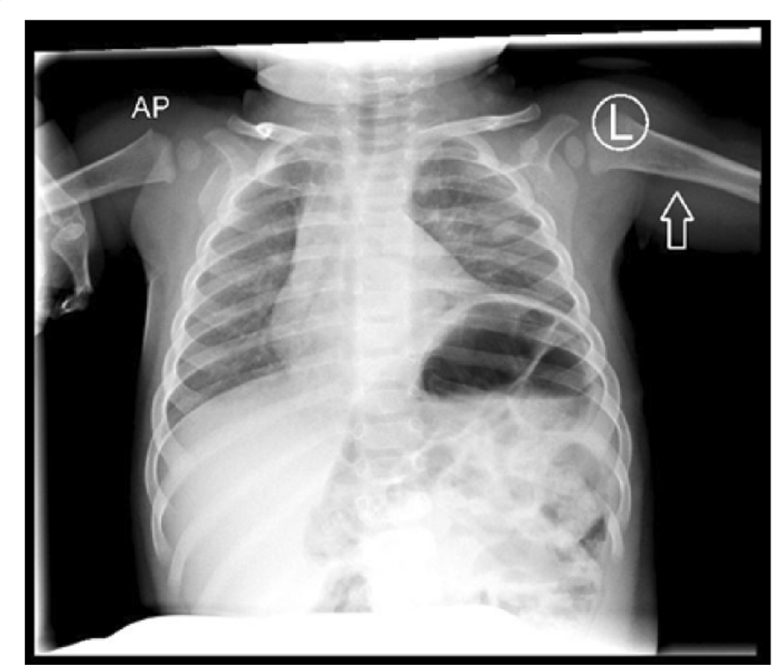

Fig. 4 Post-operative Chest X-Ray. Persistent asymptomatic left hemidiaphragm elevation demonstrated on post-operative chest X-ray

\section{Abbreviations}

CTA: Computed tomographic angiogram; EPS: Extrapulmonary sequestration

\section{Acknowledgements}

Not applicable.

Funding

There was no funding source for this case report.

Availability of data and materials

Not applicable.

Authors' contributions

LD was the primary manuscript author. CC and JG provided the clinical details. All authors read and approved the final manuscript.

\section{Ethics approval and consent to participate}

Study approval was waived by the SSM Health Cardinal Glennon Institutional Review Board.

\section{Consent for publication}

Not applicable.

\section{Competing interests}

The authors declare that they have no competing interests.

\section{Publisher's Note}

Springer Nature remains neutral with regard to jurisdictional claims in published maps and institutional affiliations.

\section{Author details}

${ }^{1}$ Department of Surgery, Univeristy of Maryland Medical Center, Baltimore 21201, USA. ${ }^{2}$ Department of Surgery, SSM Health Cardinal Glennon Children's Hospital, St. Louis 63104, USA.

Received: 16 April 2018 Accepted: 10 July 2018

Published online: 20 July 2018

\section{References}

1. Tashtoush B, Memarpour R, Gonzalez J, Gleason JB, Hadeh A. Pulmonary sequestration: a 29 patient case series and review. J Clin Diagn Res. 2015; 9(12):AC05-8.

2. Eber E. Antenatal diagnosis of congenital thoracic malformations: early surgery, late surgery, or no surgery? Semin Respir Crit Care Med. 2007;28(3): $355-66$.

3. Koontz CS, Oliva V, Gow KW, Wulkan ML. Video-assisted thoracoscopic surgical excision of cystic lung disease in children. J Pediatr Surg. 2005;40(5): 835-7.

4. Reinke $C$, Kheraini A, Rice HE. Thoracoscopic resection of an apical extralobar pulmonary sequestration in an infant. J Laparoendosc Adv Surg Tech A. 2007;17(2):252-4. 
5. Yamataka A, Koga H, Ochi T, Imashimizu K, Suzuki K, Kuwatsuru R, Lane G, Nishimura K, Inada E, Suzuki K. Pulmonary lobectomy techniques in infants and children. Pediatr Surg Int. 2017;33(4):483-95. https://doi.org/10.1007/ s00383-016-4052-5. Epub 2016 Dec 31

6. Kulaylat AN, Engbrecht BW, Hollenbeak CS, Safford SD, Cilley RE, Dillon PW. Comparing 30-day outcomes between thoracoscopic and open approaches for resection of pediatric congenital lung malformations: Evidence from NSQIP. J Pediatr Surg. 2015;50(10):1716-21. https://doi.org/10.1016/j. jpedsurg.2015.06.007. Epub 2015 Jun 20

7. Wagenaar AE, Tashiro J, Satahoo SS, Sola JE, Neville HL, Hogan AR, Perez EA. Resection of pediatric lung malformations: national trends in resource utilization \& outcomes. J Pediatr Surg. 2016;51(9):1414-20. https://doi.org/10 1016/j.jpedsurg.2016.04.020. Epub 2016 May 17

8. Kunisaki SM, Powelson IA, Haydar B, Bowshier BC, Jarboe MD, Mychaliska GB, Geiger JD, Hirschl RB. Thoracoscopic vs open lobectomy in infants and young children with congenital lung malformations. J Am Coll Surg. 2014; 218(2):261-70. https://doi.org/10.1016/j.jamcollsurg.2013.10.010. Epub 2013 Oct 24

9. Lee EY, Dillon JE, Callahan MJ, Voss SD. 3D multidetector CT angiographic evaluation of extralobar pulmonary sequestration with anomalous venous drainage into the left internal mammary vein in a paediatric patient. $\mathrm{Br} J$ Radiol. 2006;79(945):e99-102.

10. Xie D, Xie H, You X, Chen C, Jiang G. Pulmonary sequestration with aberrant arteries arising from the renal artery and the internal thoracic artery. Ann Thorac Surg. 2013;96(5):e131. https://doi.org/10.1016/j.athoracsur.2013.08.018.

11. Hattori $Y$, Negi $K$, Takeda I, Iriyama T, Sugimura S, Watanabe $K$. Intrapulmonary sequestration with arterial supply from the left internal thoracic artery: a case report. Ann Thorac Cardiovasc Surg. 2000;6(2):119-21.

Ready to submit your research? Choose BMC and benefit from:

- fast, convenient online submission

- thorough peer review by experienced researchers in your field

- rapid publication on acceptance

- support for research data, including large and complex data types

- gold Open Access which fosters wider collaboration and increased citations

- maximum visibility for your research: over $100 \mathrm{M}$ website views per year

At $\mathrm{BMC}$, research is always in progress.

Learn more biomedcentral.com/submissions 